Idarotuna, Vol. 1. No. 1. Oktober 2018

\title{
STRATEGI TAREKAT NAQSYABANDIYAH DALAM \\ PENGEMBANGAN DAKWAH DI DESA RANTAU PANJANG KIRI KECAMATAN KUBU BABUSSALAM KABUPATEN ROKAN HILIR
}

\author{
Masduki dan Jefri. R \\ Fakultas Dakwah dan Komunikasi UIN Suska Riau \\ Email: masduki@uin-suska.ac.id
}

\begin{abstract}
Penelitian ini dilatarbelakangi oleh kondisi saat ini yaitu orang yang melaksanakan persulukan semakin lama semakin berkurang. Hal ini disebabkan karena orang-orang yang berkecimpung didalamnya telah berpulang kerahmatullah, dan kurangnya minat generasi muda untuk terlibat dalam tarekat ini, sebagai ajang generasi penerus. Apabila kondisi ini dibiarkan berlarut-larut akan menyebabkan keterpurukan terhadap ajaran tarekat itu sendiri. Tarekat merupakan suatu jalan untuk mendekatkan diri kepada Allah SWT. dengan kaedahkaedah atau aturan-aturan tertentu sesuai syari'at yang diyakini dengan sepenuh hati dari guru (mursyid) dalam penyucian diri dengan berkhalwat. Tarekat Naqsyabandiyah, yang berhaluan kepada Ahlussunnah waljama'ah bermazhabkan kepada As-syafi'iyah. Kemudian Tarekat Naqsyabandiyah mengajarkan zikir-zikir yang sangat sederhana, lebih mengutamakan zikir hati dari pada zikir mulut. Jika diringkas tujuan pokok dari Tarekat Naqsyabandiyah adalah taubat, uzlah, zuhud, taqwa, qana'ah, dan taslim. Untuk mendapatkan bagaimana strategi Tarekat Naqsyabandiyah dalam pengembangan dakwahnya adalah dengan mewawancarai informan penelitian, mengobservasi dan dokumentasi. Agar Tarekat Naqsyabandiyah tetap tumbuh dan berkembang tergantung kepada Mursyid. Seorang Mursyid tidak boleh cacat fisik maupun non-fisik dikalangan masyarakat. Pembenahan yang paling utama untuk diperbaiki adalah komunikasi. Baik Mursyid, murid maupun masyarakat hendaknya saling mendukung dalam pembangunan fisik, mental dan spritual. Untuk memudahkan dalam pengembangan dakwah tarekat Naqsyabandiyah ini, hendaknya menjalin hubungan baik dengan pemerintah sehingga dalam urusan fasilitas terpenuhui. Penyebab dari kegelisahan masyarakat untuk masuk adalah masalah perekonomian yang kurang mampu.
\end{abstract}

Keywords : Strategi Dakwah, Tarekat Naqsyabandiyah, Pengembangan Dakwah 


\section{Pendahuluan}

Perjalanan sejarah dakwah telah mencatat banyak perkembangan dakwah sejak zaman Rasulullah SAW sampai dewasa ini telah mengalami pasang-surut. Seiring dengan perjalanan ini, sejarah mencatat banyak terdapat aliran-aliran maupun firqoh-firqoh di dunia dakwah. Disamping adanya aliran-aliran maupun firqoh-firqoh tersebut, telah banyak Da'i dan Dai'ah yang meneruskan dakwah Rasulullah SAW dengan menggunakan berbagai strategi dalam menyampaikan dakwahnya, misalnya ceramah dari mimbar ke mimbar.

Agama Islam sebagai Agama Rahmatallil'alamin, membawa manusia ke jalan yang benar menjauhi diri dari perbuatan keji dan mungkar sehingga terciptalah amar ma'ruf. Disamping aliranaliran dan firqoh-firqoh yang ada, terdapat juga Tarekat yang sejak dahulu telah berkembang dan sampai saat ini semakin banyak pengikutnya. Tarekat yang hadir ditengah-tengah umat Islam juga dibagi ke dalam beberapa kelompok yang memiliki ciri khas mmasing-masing. Tarekat merupakan suatu jalur atau jalan untuk mendekatkan diri kepada Allah SWT dengan kaedah-kaedah atau aturan-aturan tertentu sesuai syari'at ${ }^{1}$ yang mana suatu jalan itu diyakini dengan sepenuh hati dari guru (mursyid) yang telah mereka ikuti, ${ }^{2}$ dalam penyucian diri dengan berkhalwat. Diantara Tarekat tersebut salah satunya

\footnotetext{
${ }^{1}$ Tarekat adalah suatu jalan atau metode tertentu dalam ibadah yang dilakukan oleh seorang sufi dan diikuti oleh para muridnya dengan tujuan bisa berada sedekat mungkin dengan Allah SWT. Rusli, Ris'an, Tasawuf dan Tarekat (studi pemikiran dan pengalaman sufi) (Jakarta: Rajawali Pers, 2013), 187.

${ }^{2}$ Dalam perkembangan selanjutnya tarekat digunakan sebagai suatu kelompok yang dipimpin oleh seorang syaikh yang diikuti oleh muridnya dalam rangka mendekatkan diri kepada Allah SWT. Dan juga tarekat dihubungkan dengan gurunya berarti keterkaitan antara murid dengan murid dan juga dengan gurunya yaitu persaudaraan yang kuat di antara mereka. Rusli, Ris'an, Tasawuf dan Tarekat (studi pemikiran dan pengalaman sufi), 187.
}

Tarekat Naqsyabandiyah yang semakin berkembang ke berbagai daerah. Salah satunya berkembang di Desa Rantau Panjang Kiri Kecamatan Kubu Babussalam Kabupaten Rokan Hilir.

Tarekat Naqsyabandiyah berhaluan kepada Ahlussunnah waljama'ah bermazhabkan kepada As-syafi'iyah. Tarekat Naqsyabandiyah mengajarkan zikir-zikir yang sangat sederhana, lebih mengutamakan zikir hati daripada zikir mulut. Jika diringkas tujuan pokok dari Tarekat Naqsyabandiyah adalah taubat, uzlah, zuhud, taqwa, qana'ah, dan taslim. ${ }^{3}$ Tarekat Naqsyabandiyah dalam perkembangannya telah banyak pengikutnya dari berbagai kalangan. Awal mulanya Tarekat ini masuk, sangatlah direspon baik oleh masyarakat setempat terutama dikalangan orang-orang tua yang biasanya di Desa tersebut dengan sebutan "kaum tua", yang mana dalam Tarekat ini, melakukan berbagai kegiatan amalan antara murid dan guru (mursyid) yang dilakukan disebuah tempat diberi nama rumah persulukan atau rumah suluk.

Di Desa Rantau Panjang Kiri ini, terdapat beberapa tempat persulukan dan beberapa guru (mursyid). Persulukan ini dilakukan pada bulan-bulan tertentu, mengikuti perjalanan bulan-bulan arab, misalnya; bulan muharram, rabi'ul awal, rajab, sya'ban, dan yang terkhusus di bulan ramadhan. Namun, dalam melaksanakan persulukan itu, dibeberapa persulukan yang ada di desa Rantau Panjang Kiri ini berbeda-beda bulannya kecuali di bulan ramadhan.

Melihat kondisi saat ini, orang yang melaksanakan persulukan semakin

\footnotetext{
${ }^{3}$ Rusli, Ris'an, Tasawuf dan Tarekat (studi pemikiran dan pengalaman sufi), 216.

${ }^{4}$ Kaum tua ini merupakan penamaan masyarakat, terhadap orang-orang yang pemahamannya secara turun-temurun, dari datukneneknya terhadap suatu keyakinan yang mereka yakini berbau Sunah Nabi SAW senantiasa diberi nama dengan Ahlussunnah Waljama'ah bermazhabkan As-syafi'iyah. (ujar tetua KubuKubu Babussalam H. Samuel Matwafa).
} 
lama semakin berkurang. Hal itu, disebabkan karena orang-orang yang berkecimpung di dalamnya telah berpulang kerahmatullah, dan kurangnya minat generasi muda untuk terlibat dalam tarekat ini. Jika kondisi ini dibiarkan akan menyebabkan keterpurukan terhadap ajaran tarekat itu sendiri. Oleh sebab itu, penulis ingin mengetahui lebih dalamnya lagi mengapa hal yang demikian bisa terjadi. Akhirnya, penulis ingin menulis seperti apa sebenarnya strategi yang digunakan oleh guru (mursyid) dalam merekrut muri dengan judul: "Strategi Tarekat Naqsyabandiyah dalam Pengembangan Dakwah di Desa Rantau Panjang Kiri Kecamatan Kubu Babussalam Kabupaten Rokan Hilir”.

\section{Kajian Teori}

\section{Strategi}

Menurut Skinner strategi merupakan filosofi yang berkaitan dengan alat untuk mencapai tujuan. ${ }^{5}$ Strategi dakwah dapat diartikan sebagai usaha manajerial menumbuhkembangkan kekuatan organisasi dakwah untuk mengeksploitasi peluang dakwah yang muncul guna mencapai tujuan organisasi yang telah ditetapkan agar sesuai dengan misi yang telah ditetapkan. Pengertian tersebut mempunyai implikasi bahwa organisasi dakwah harus berusaha melakukan adaptasi dengan lingkungan dakwah. Artinya organisasi dakwah berusaha untuk mengurangi efek negatif yang ditimbulkan oleh ancaman dakwah. ${ }^{6}$ Dengan demikian, strategi di sini diartikan sebagai cara dalam berdakwah.

\section{Pengembangan Dakwah}

Mengenai pengembangan dakwah Tarekat Naqsyabandiyah ini, dapat dinukilkan mengenai seorang

\footnotetext{
${ }^{5}$ Akdon, Strategic Management For Educational Management, ( Bandung: Alfabeta, 2009) 4-5.

${ }^{6}$ Achyar, Eldin, Dakwah Stratejik (Jakarta: Pustaka Tarbiatuna, 2003), 72.
}

Syaikh Tarekat Naqsyabandiyah yaitu Syaikh Abdul Wahab Rokan, pada tahun $1285 \mathrm{H} / 1869 \mathrm{M}$, dalam usia 58 tahun beliau membangun sebuah kampung di wilayah Kubu, dinamainya "Kampung Mesjid". Kampung baru ini dijadikannya atau basis bagi usahausahanya menyebarkan agama ke daerah-daerahnya sekitarnya, seperti ke Kualuh, Panai, Bilah, Kota Pinang, Kabupaten Labuhan Batu (Sumatera Utara), Dumai, Bengkalis, Pekanbaru (Propinsi Riau) dan Sungai Ujung (Malasyia). Dari hari ke hari muridnya bertambah. Pembinaan kader juru dakwah dilaksanakan secara intensif dan terarah. Akibatnya banyaklah lahir fakih-fakih, khalifah-khalifah dan guruguru Tarekat Naqsyabandiyah. ${ }^{7}$

Dalam pengertian secara terminologi, Masdar Helmy mengatakan bahwa dakwah adalah mengajak dan menggerakkan manusia termasuk agar mentaati ajaran-ajaran Allah (Islam) termasuk amar ma'ruf nahi munkar untuk bisa memperoleh kebahagian di dunia dan akhirat. ${ }^{8}$

Jadi, strategi dakwah merupakan sebuah konsep yang memuat langkahlangkah yang terarah dan terpadu dalam mendayagunakan segala potensi yang dimiliki untuk mengembangkan efektivitas dakwah untuk kelompok sasaran (mad'u) tertentu, dengan mempertimbangkan berbagai kendala dan tantangan yang dihadapi. Sebagai aktivitas yang integral, dakwah dapat dilakukan lewat berbagai jalur kehidupan, seperti sosial, ekonomi, ilmu dan teknologi, pendidikan dan kesenian. $^{9}$

\section{Pengertian Tarekat}

\footnotetext{
${ }^{7}$ Ahmad Fuad Said, Sejarah Syaikh Abdul Wahab Tuan Guru Babussalam (Medan: Pustaka Babussalam, 1976), 34.

${ }^{8}$ Moh. Ali Aziz, Ilmu Dakwah (Jakarta: Kencana, 2004), 5-6.

${ }^{9}$ Din, Syamsuddin, Etika Agama dalam Membangun Msyarakat Madani, (Jakarta: PT Logos Wacana Ilmu, 2002) 127.
} 
Tarekat adalah sebuah istilah yang diturunkan dari ayat Al-Qur'an Surah al-Jinn ayat $16,{ }^{10}$ sebagai berikut:

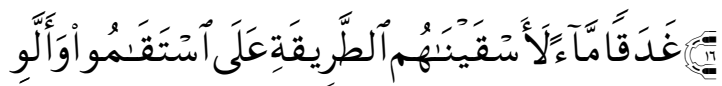

Artinya:

"Dan bahwasanya jikalau mereka tetap berjalan lurus di atas jalan itu (agama Islam), benar-benar Kami akan memberi minum kepada mereka air yang segar (rezeki yang banyak)." (QS. al-Jinn [72] : 16). ${ }^{11}$

Arti thariqah dalam ayat tersebut dijelaskkan lebih jauh dalam sebuah hadits yang diriwayatkan oleh Bukhari dan Muslim, yang di dalamnya Nabi SAW. menyuruh umatnya untuk mengikuti Sunah beliau dan Sunah para sahabatnya. Kedua kata itu sunah dan thariqah, memiliki makna yang sama, yaitu "jalan". Jadi, istilah thariqah dapat diterapkan pada berbagai kelompok orang yang mengikuti mazhab pemikiran yang dikembangkan oleh seorang alim atau syaikh tertentu. ${ }^{12}$

Tarekat berdasarkan bahasa Arab yaitu "Thariqah" yang oleh Luis al-Makluf dalam kitab al-Munjid diartikan sebagai jalan, keadaan atau aliran dalam garis tertentu. Tarekat juga dapat dipahami sebagai metode atau petunjuk dalam melaksanakan sesuatu ibadah sesuai dengan ajaran atau bimbingan yang diberikan oleh seorang guru atau Syaikh terhadap muridmuridnya (pengikutnya). ${ }^{13}$

\footnotetext{
${ }^{10}$ Syekh, Muhammad Hisyam Kabbani, Tasawuf dan Ihsan AntiVirus Kebatilan dan Kezaliman (Jakarta: Serambi, 2007), 16.

${ }^{11}$ Al-Qur'an dan Terjemahan, Departemen Agama RI, 573.

${ }^{12}$ Syekh, Muhammad Hisyam Kabbani, Tasawuf dan Ihsan AntiVirus Kebatilan dan Kezaliman, 16.

${ }^{13}$ Perdamaian, Akhlak Tasauf (Pekanbaru: Unri Press, 2010), 181.
}

\begin{abstract}
Al-Palembani, ${ }^{14}$ menguraikan syarat bagi setiap orang yang ingin
\end{abstract} mengikuti tarekat, yaitu: ${ }^{15}$ Pertama, Bertakwa kepada Allah SWT dengan sebenar-benar takwa. Kedua, Menyiapkan diri dengan senjata zikir. Ketiga, Tunduk secara total kepada Syaikh seperti mayat di hadapan petugas yang memandikan. Keempat, Bertekad bulat untuk tetap dalam tarekat hingga akhir hayatnya. Dan, Kelima, Harus memiliki kawan tetap dalam menjalankan ibadah secara bersama-sama membaca wirid bersama, dan tolong-menolong demi kebaikan.

Selanjutnya, al-Palembani mensyaratkan untuk berhati-hati dalam tarekat, sebab pengikut tarekat harus memperhatikan kewajibankewajibannya, yaitu: Pertama, Membatasi makan, sebagai prasyarat terbukanya pintu hati. Kedua, Berjaga ditengah malam untuk melakukan ibadah karena sebagai prasyarat kesucian hati. Ketiga, Disiplin dalam menjaga ucapan karena akan menutup pintu makrifat. Dan, Keempat, Meditasi dan khalwat ditempat khusus dengan mengikuti petunjuk-petunjuk Syaikh agar hati merasa hadir disisi Allah SWT.

Adapun cara tarekat untuk bersatu dengan Tuhan ada beberapa konsep, antara lain: Pertama, Hulul (Tuhan menjelma ke dalam insan) seperti ajaran al-Hallaj. Kedua, alIsyraq (cahaya dari segala cahaya) seperti ajaran Abul Futuh asSuhrawardi. Ketiga, Ittihad (Tuhan dan hamba berpadu menjadi satu) seperti ajaran Abu Yazid al-Bushthami. Keempat, Ittisal (hamba dapat

\footnotetext{
${ }^{14}$ Al-Palembani lahir di Palembang sekitar tiga atau empat tahun setelah $1112 \mathrm{H}$. Menurut kitabnya, Sair al-Salikin baru ditulisnya tahun 1192 H/ 1779 M, ketika ia berusia sekitar 75 tahun .Sri, Mulyati, Tasawuf Nusantara (Rangkaian Mutiara Sufi Terkemuka) (Jakarta: Kencana, 2006), 106.

${ }^{15}$ Totok, Jumantoro dan Samsul, Munir Amin, Kamus Ilmu Tasawuf (Wonosobo: Amzah, 2005), 240-241
} 
menghubungkan diri dengan Tuhan dan menentang paham hulul dari al-Halajj).

\section{Tarekat Naqsyabandiyah}

Tarekat Naqsyabandiyah adalah sebuah Tarekat yang mempunyai dampak dan pengaruh yang sangat besar kepada masyarakat Muslim di berbagai wilayah yang berbeda-beda. Tarekat ini pertama kali berdiri di Asia Tengah kemudian meluas ke Turki, Suriah, Afganistan dan India. ${ }^{16}$

Pendiri Tarekat Naqsaybandiyah adalah seorang pemuka tasawuf terkenal yakni, Muhammad bin Muhammad Baha' al-Din al-Uwaisi alBukhari Naqsyabandiyah (717 H/1318 M-791 H/1389 M), ${ }^{17}$ dilahirkan di sebuah Desa Qashrul Arifah, kurang lebih 4 mil dari Bukhara tempat lahir Imam Bukhari. Tarekat Naqsyabandiyah, karena Syaikh Muhammad Bahauddin pendiri tarekat ini, yang senantiasa berzikir mengingat Allah berkepanjangan, sehingga lafaz jalalah "Allah" itu terukir dan melekat dalam kalbunya. Selanjutnya Amin alKurdi menerangkan pula bahwa beliau pernah mendengar keterangan dari beberapa orang Khalifah Naqsyabandiah yang menyatakan bahwa Rasulullah SAW. pernah meletakan telapak tangannya ke jantung hati Syaikh Bahauddin ketika beliau sedang muraqabah, sehingga berbekas terukir di dalam hatinya. ${ }^{18}$

$$
\text { Adapun silsilah Tarekat }
$$

Naqsyabandiyah menurut Amin alKurdi dalam kitabnya "Tanwirul Qulub" yaitu: Nabi Muhammad SAW, Abu Bakar Shiddiq, Salman al-Farisi, Qasim bin Muhammad, Imam Ja' far asShadiq, Abu Yazid al-Busthami, Abu Hasan Ali bin Ja'far al-Kharqani, Abu

\footnotetext{
${ }^{16}$ Sri, $\quad$ Mulyati,Tarekat-tarekat Muktabarah di Indonesia, (Jakarta: Kencana, 2011), 91.

${ }^{17}$ Sri, Mulyati, Tarekat-tarekat Muktabarah di Indonesia, 89.

${ }^{18}$ Ahmad, Fuad Said, Sejarah Syaikh Abdul Wahab Tuan Guru Babussalam, 105.
}

Ali al-Fadhal bin Muhammad al-Thusi al-Farmadi, Abu Ya'kub al-Hamdani bin Aiyub bin Yusuf bin Husin, Abdul Khaliq al-Fajduani bin al-Imam Abdul Jamil, Arif al-Riyukuri, Mahmud alAnjiru al-Faghnawi, Ali al-Ramituni, Muhammad Babusamasi, Amir Kulal bin Sayid Hamzah, Bahauddin Naqsyabandi.

Kemudian silsilah tersebut berkelanjutan sampai kepada Syaikh Abdul Wahab Rokan al-Khalidi Naqsyabandi, sesuai ijazah yang diperoleh beliau, adapun silsilah tersebut yaitu: Muhammad Bukhari, Ya'kub Yarkhi Hishari, Abdullah Samarkandi (Ubaidullah), Muhammad Zahid, Muhammad Darwis, Khawajiki, Muhammad Baqi, Ahmad Faruqi, Muhammad Ma'shum, Abdullah Hindi, Dhiyaul Haq, Ismail Jawi Minagkabawi, Abdullah Affandi, Syaikh Sulaiman, Sulaiman Zuhdi, Abdul Wahab Jawi Rokan al-Khalidi Naqsyabandi.

Ciri menonjol Tarekat Naqsyabandiyah adalah Pertama, diikutinya syari'at secara ketat, keseriusan dalam beribadah yang menyebabkan penolakan terhadap musik dan tari dan lebih menyukai berzikir dalam hati. Kedua, upaya yang serius dalam memengaruhi kehidupan dan pemikiran golongan penguasa serta mendekatkan Negara pada Agama. ${ }^{19}$

\section{Unsur-unsur dan Asas Ajaran serta Paham Tarekat Naqsyabandiyah}

a. Guru (mursyid)

Adapun yang dinamakan guru disini adalah seorang manusia zahir atau ghaib yang mengajar seseorang di dalam suatu ilmu dan guru ini akan menyampaikan petunjuk, petua atau kaedah-kaedah tentang ilmu tersebut.

\footnotetext{
${ }^{19}$ Sri, Mulyati, Tarekat-tarekat Muktabarah di Indonesia, 91.
} 
Guru yang mursyid adalah orang yang tinggi martabatnya di dalam ilmu hakikat dan makrifat, karena semasa perjalanan pencarian dan perguruannya dahulu. Orang yang menjadi guru harus dan telah mengalami sendiri pengalaman pengajaran laduni, yang kebanyakannya ilmu laduni ini membicarakan hal-hal ilmu ghaib yang keluar dari akal pencapaian pemikiran manusia. $^{20}$

Guru yang berpengalaman berasal dari seorang guru yang pernah diijazahkan oleh guru asalnya untuk mewariskan ilmunya kepada calon muridnya yang baru. Ijazah ini sangat perlu, sebab tanpa keizinan (rekomendasi) dari guru asalnya untuk mengajar kepada calon muridnya yang baru, maka mata rantai emas jalan hakiki dan makrifat tidak bersambung dari guru asalnya, yaitu Rasulullah SAW. ${ }^{21}$

Menurut Syaikh Abu Hasan Asy-Syadzili sebagaimana dikutip Ahmad bin Muhammad bin Iyyadh dalam kitab alMufakhir al-Aliyah bahwa syarat-syarat mursyid minimal ada lima, yaitu: 1)Memiliki sentuhan rasa rohani yang jelas dan tegas; 2) Memiliki pengetahuan yang benar. 3) Memiliki cita (himmah) yang luhur; 4) Memiliki mata hati yang tajam untuk menunjukkan jalan Ilahi; 5) Memiliki prilaku rohani yang diridhai. ${ }^{22}$

b. Murid (pengikut)

${ }^{20}$ Zulkifli dan Sentot Budi Santoso, WUJUD (Menuju Jalan Kebenaran),(Solo: CV Mutiara Kertas) 107.

${ }^{21}$ Zulkifli dan Sentot Budi Santoso, WUJUD (Menuju Jalan Kebenaran), 110-111.

${ }^{22}$ Totok, Jumantoro dan Samsul, Munir Amin, Kamus Ilmu Tasawuf, 154-155.
Murid menurut Syaikh alHadad adalah seseorang yang motivasi amalnya hanya tertuju kepada Allah SWT. dan itu dapat terlihat pada semua gerak lahir maupun batinnya, baik dalam hubungan yang bersifat horizontal maupun vetikal. ${ }^{23}$ Murid adalah orang yang menghendaki pengetahuan dan petunjuk dalam amal ibadah. Setelah murid berbai'at kepada sang guru maka ia terikat dengan etika sufi, menyerahkan diri sebulatbulatnya kepada guru, tidak menentang atau menolak atau bertanya kepadanya, tidak boleh melepaskan ikhtiar-nya dengan ikhtiar gurunya, tidak boleh menafsirkan kejadian semaunya sendiri, harus menyimpan rahasia gurunya, menjaga guru dan keluarganya, merendahkan diri kepadanya dan sebagainya. ${ }^{24}$

Menurut Syhabuddin Umar Suhrawardi, ada lima belas adab atau aturan prilaku yang harus diamalkan murid, antara lain: 1) Keyakinan penuh kepada Syaikh dalam ajaran, bimbingan, dan penyuciannya atas diri muridmuridnya; 2)Ketetapan hati yang sempurna untuk mendatangi Syaikh; 3)Mematuhi perintah Syaikh; 4)Tidak melawan; 5)Menafikan kehendak dan keinginannya sendiri; 6) Selalu menghargai pemikiran Syaikh; 7)Mengacu pada pengetahuan Syaikh dalam menjelaskan makna berbagai macam mimpi; 8) Menghormati ucapan Syaikh; 9)Merendahkan suara; 10) Menahan diri dari tindakan di luar batas; 11)Mengetahui waktu yang tepat untuk berbicara; 12)

\footnotetext{
${ }^{23}$ Totok, Jumantoro dan Samsul, Munir Amin, Kamus Ilmu Tasawuf, 153.

${ }^{24}$ Totok, Jumantoro dan Samsul, Munir Amin, Kamus Ilmu Tasawuf,241.
} 
Menjaga batas kehormatannya sendiri; 13)Mampu menjaga rahasia-rahasia Syaikh; 14) Mengungkapkan berbagai rahasianya sendiri kepada Syaikh. 15) Berbicara kepada Syaikh sesuai dengan kadar pemahaman pendengar lainnya. ${ }^{25}$

c. Asas Ajaran dan Paham Tarekat Naqsyabandiyah

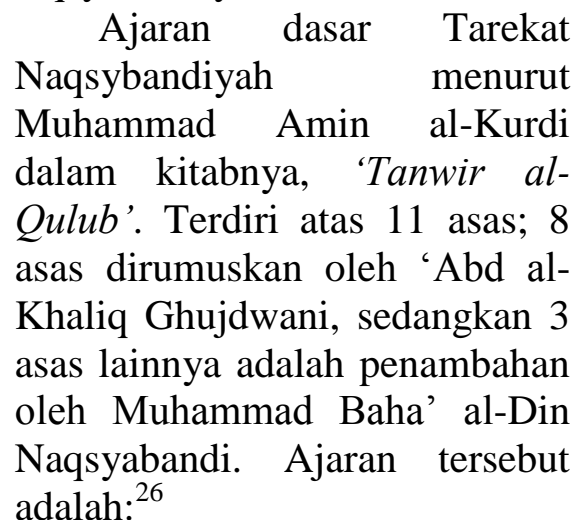

1. Husy dar dam,"sadar sewaktu bernafas". Suatu latihan konsentrasi dimana seseorang harus menjaga diri dari kekhilafan dan kealpaan ketika kelur masuk nafas, supaya hati selalu merasakan kehadiran Allah SWT.. ${ }^{27}$

2. Nazhar bar qadam, "menjaga langkah". Seorang murid yang sedang menjalani khalwat suluk, bila berjalan harus menundukkan kepala, melihat kearah kaki. Sebab memandang kepada aneka ragam ukiran dan warna dapat melalaikan orang dari menginggat Allah SWT selain itu juga supaya tujuantujuan yang (rohaninya) tidak dikacaukan oleh segala hal

\footnotetext{
${ }^{25}$ Totok, Jumantoro dan SamsulMunir Amin, Kamus Ilmu Tasawuf, 154.

${ }^{26}$ Sri, Mulyati, Tarekat-tarekat Muktabarah di Indonesia,102-105.

${ }^{27}$ Penyusun, Dewan Redaksi Enseklopedi Islam, Enseklopedi Islam, (Jakarta: PT Ichtiar Baru van Hoeve, 2001),8.
}

yang berada disekelilingnya yang tidak relevan.

3. Safar dar wathan, "melakukan perjalannya di tanah kelahirannya”. Maknannya adalah melakukan perjalanan batin dengan meninggalkan segala bentuk

ketidaksempurnaannya

sebagai manusia menuju kesadaran akan hakikatnya sebagai makhluk yang mulia. $^{28}$

4. Khalwat dar anjuman, "sepi $d i$ tengah keramaian”. Khalwat bermakna menyepinya seorang pertapa, sementara anjuman dapat berarti perkumpulan tertentu. Berkhalwat terbagi pada dua bagian, yaitu: Pertama, Khalwat lahir, adalah orang yang bersuluk mengasingkan diri ke sebuah tempat tersisih dari masyarakat ramai. Kedua,khalwat batin, adalah mata hati menyaksikan rahasia kebesaran Allah SWT dalam pergaulan sesama makhluk.

5. Yad krad, "ingat atau menyebut". Ialah berzikir terus-menerus mengingat Allah SWT baik zikir ism aldzat (menyebut Allah), mau pun zikir nafi itsbat ( menyebut La Ilaha illa Allah).

6. Baz Gasht, "kembali", "memperbarui". Hal ini dilakukan untuk mengendalikan hati agar tidak condong kepada hal-hal yang menyimpang (melantur). Menjaga pemikiran sendiri dengan

\footnotetext{
${ }^{28}$ Penyusun, Dewan Redaksi Enseklopedi Islam, Enseklopedi Islam, 8.
} 
mengulangi zikir sesudah meresapkan kalimat "Ilahi anta maqshudi wa ridhaka mathlubi", artinya adalah Wahai Tuhanku, Engkaulah tujuanku dan keridhaan-Mu merupakan tuntutanku.

7. Nigah Dasyt, "waspada". Ialah setiap murid harus menjaga hati, pikiran dan perasaan dari sesuatu walau sekejap ketika melakukan zikir tauhid.

8. Yad Dasyt, "mengingat kembali". Adalah tawajuh (menghadapkan diri) kepada Nur Dzat Allah Yang Maha Esa, tanpa berkata-kata. Pada hakikatnya menghadapkan diri dan mencurahkan perhatian kepada Nur Dzat Allah itu tiada lurus, kecuali sesudah fana (hilang kesadaran diri) yang sempurna.

Adapun tiga asas lainnya yang berasal dari Syaikh Baha' al-Din Naqsyabandi adalah:

1. Wukuf zamani, "memeriksa penggunaan waktu”. Yaitu orang yang bersuluk senantiasa selalu mengamati dan memerhatikan dengan teratur keadaan dirinya setiap dua atau tiga jam sekali. Apabila ternyata keadaannya terus sadar dan tengelam dalam zikir dan melakukan yang terpuji, maka hendaklah ia bersyukur kepada-Nya. Sebaliknya apabila keadaannya dalam alpa atau lalai dan melakukan perbuatan dosa, maka harus segera minta ampun dan tobat kepada Allah SWT serta kembali kehadiran hati yang sempurna.

2. Wukuf 'adadi, "memeriksa hitungan zikir”. Yaitu dengan penuh hati-hati (konsentrasi penuh) memelihara bilangan ganjil pada zikir nafi itsbat, 3 atau 5 sampai 21 kali.

3. Wukuf qalbi, "menjaga hati tetap terkontrol". Adalah kehadiran hati serta kebenaran tiada yang tersisa, sehingga perhatian seseorang secara sempurna sejalan dengan zikir dan maknanya.

d. Paham Ahlussunnah waljama'ah Istilah ahlussunnah waljama'ah dinisbahkan pada aliran teologi Asy'ariyah dan Maturidiyah karena mereka berpegang kuat kepada sunnah Nabi SAW dan juga merupakan kelompok mayoritas dalam masyarakat Islam. Ahlussunnah waljama'ah oleh al-Asy'ari juga disebut sebagai Ahl al-Hadits wa as-Sunnah (Golongan yang berpegang pada hadits dan sunnah) dalam kitabnya yang berjudul Maqalat al-Islamiyyin (berisi tentang aliran-aliran teologi dan pandangannya dalam Islam). Dalam kitabnya yang lain, al-Ibanah (Penjelasan), istilah ini dipergunakan kata-kata Ahl alhaqq wa as-Sunnah (Golongan yang berpegang pada kebenaran dan sunnah Nabi SAW). Aliran ahlussunnah waljama'ah ini sering juga disebut golongan Suni. ${ }^{29}$

e. Persulukan atau Suluk

Suluk di dalam istilah tasawuf adalah jalan atau cara mendekatkan diri kepada Allah SWT atau cara memperoleh makrifat. ${ }^{30}$ Makna lateral suluk adalah menempuh jalan yang merupakan suatu tindakan fisik dan bisa dipandang sebagai

\footnotetext{
${ }^{29}$ Penyusun, Dewan Redaksi Enseklopedi Islam, Enseklopedi Islam, 80.

${ }^{30}$ Penyusun, Dewan Redaksi Enseklopedi Islam, Enseklopedi Islam, 292.
} 
gerakan dalam dimensi ruang. Hanya saja, dalam istilah teknis, yang dimaksud suluk adalah perjalanan spiritual, dan bukan gerakan dalam dimensi ruang. ${ }^{31}$

$\begin{array}{ccc}\text { Dalam } & \text { kajian } & \text { Mir } \\ \text { ValiudinSuluk } & \text { ada } & \text { tiga } \\ \text { jenis: }{ }^{32} \text { Pertama, } & \text { Suluk } & \text { Qalb }\end{array}$ (tashfiyah al-qalb) adalah penyucian kalbu atau hati; Kedua, Suluk Ruh (takhalliyah as-sirr) secara harfiyah berarti rahasia, yakni sebuah organ pemahaman spiritual, disebut Takhalliyah assirr atau pengosongan sirr; Dan, Ketiga, Suluk sirr (tajalliyah arruh), jiwa sebuah organ kontemplasi mistis. Diungkapkan dengan tajalliyah ar-ruh atau pencerahan ruh, ini berarti mengisi jiwa dengan visi tentang Allah dan gelora cinta-Nya.

\section{Strategi Dakwah Tarekat Naqsyabandiyah dalam merekrut masyarakat di Desa Rantau Panjang Kiri}

Adapun strategi r tarekat
naqsyabandiyah dalam merekrut
masyarakat di desa Rantau Panjang Kiri
dusun Tanjung Masjid I yaitu melalui
perkumpulan seperti: wirid atau pengajian
dan acara peringatan hari besar Islam,
perbincangan dengan perkataan yang baik,
bersilaturrahmi ke rumah-rumah terutama
ke rumah sanak keluarga terdekat,
kemudian memberikan pesan ghaib/ilmu
kebatinan untuk mendekatkan diri kepada
Allah SWT.

Begitu pula dengan tarekat naqsyabandiyah dusun Tanjung Masjid II desa Rantau Panjang Kiri juga memiliki strategi dalam merekrut masyarakat, seperti: memberikan peluang besar kepada para khalifah yang telah mengikuti tarekat naqsyabandiyah untuk membantu

\footnotetext{
${ }^{31}$ Totok, Jumantoro dan Samsul, Munir Amin, Kamus Ilmu Tasawuf, 211-213.

${ }^{32}$ Totok, Jumantoro dan Samsul, Munir Amin, Kamus Ilmu Tasawuf, 212-213.
}

pekerjaan Mursyid (guru) dalam mengajak yang lainnya, memberikan peluang besar dalam perekonomian (digratiskan) fasilitas, memberikan pengajian kepada masyarakat pada hari-hari besar Islam dan pada hari Haul Almarhum Tuan Syaikh H. Abdul Wahid Bin H. Abdul Fatah selaku pendiri Tarekat Naqsyabandiyah (suluk) ini, di Dusun Tanjung Masjid II.

\section{Strategi dakwah terhadap masyarakat yang telah mengikuti Tarekat Naqsyabandiyah di Desa Rantau Panjang Kiri}

Adapun strategi dakwah terhadap masyarakat yang telah mengikuti tarekat naqsabandiyah di dusun Tanjung Masjid I desa Rantau Panjang Kiri yaitu: mengajarkan kepada murid tentang keutamaan adab ketimbang ilmu, sering menjalin komunikasi yang baik antara mursyid dan murid, dan pemberitahuan beberapa minggu sebelum masuk untuk melaksanakan persulukan.

Begitu pula dengan tarekat naqsabandiyah yang ada di dusun Tanjung Masjid II desa Rantau Panjang Kiri melakukan dakwah terhadap masyarakat yang telah mengikuti tarekat tersebut dengan cara: mursyid menjelaskan kepada muridnya tentang etika dan adab dalam bersuluk, mursyid menjelaskan kepada murid bahwa dalam tarekat naqsyabandiyah tidak boleh melupakan mursyid, ditekankan kepada murid yang telah mengikuti tarekat naqsyabandiyah untuk selalu hadir dalam Khatam Tawajuh pada malam Selasa dan malam Jum'at (diluar persulukan).

\section{Strategi pelaksanaan ajaran-ajaran Tarekat Naqsyabandiyah kepada masyarakat di Desa Rantau Panjang Kiri}

Hal-hal yang berkaitan dengan ajaran Tarekat yaitu terfokus kepada dzikir di dalam hati (dzikir qolbu) dan ajaran yang berhaluan kepada Ahlussunnah Waljamaah bermazhabkan kepada Assyafi'iyah. Adapun strategi tarekat 
naqsabandiyah di dusun Tanjung Masjid I desa Rantau Panjang Kiri dalam pelaksanaan ajaran-ajaran tarekatnya yaitu dengan cara menekankan kepada syarat 10 (sepuluh) sebelum berdzikir, yaitu: pertama, menghimpunkan segala pengenalan dalam hati; kedua, menghadapkan diri kehadirat Allah SWT.; ketiga, membaca istigfar sekurangkurangnya 3 (tiga) kali; keempat, membaca Al-Fatihah dan Surah Al-Ikhlas; kelima, menghadirkan Roh Syaikh Tarekat Naqsyabandiyah; keenam, menghadiahkan pahalanya kepada Syaikh Tarekat Naqsyabandiyah; ketujuh, memandang "Rabithah" dengan mata hati; kedelapan, mematikan diri sebelum mati; kesembilan, munajat dengan menyebut "ilahi anta maqshudi wa-ridhakamathlubi"; kesepuluh, berdzikir dengan mengucapkan kata-kata "Allah" dalam hati memejamkan mata, bersimpuh kiri, menggunci gigi, menongkatkan lidah ke langit-langit mulut dan menutupi muka dengan berselubung. ${ }^{33}$ Kemudian mengedepankan dzikir qolbu. Aspek yang dikedepankan adalah pemandangan, pendengaran, perasaan serta penglihatan mata bathin.

Adapun strategi dakwah tarekat naqsabandiyah di dusun Tanjung Masjid II desa Rantau Panjang Kiri dalam pelaksanaan ajaran-ajaran tarekatnya yaitu: 1) Ajaran yang dilakukan dalam tarekat naqsyabandiyah adalah ajaran yang berhaluan kepada Ahlusunnah Waljamaah; 2) Mengajarkan Dzikir Qolbu; 3) Dzikir yang diamalkan adalah dzikir yang diajarkan oleh mursyid; 4) Ilmu, adalah ilmu yang berkaitan dengan Ilmu Tarekat Naqsyabandiyah (suluk), terutama Ilmu Laduni; 5) Dakwah, adalah penyampaian pengajian yang diisi pada waktu luang jamaah.

\section{Strategi dalam mempertahankan ajaran Tarekat Naqsyabandiyah yang telah}

\footnotetext{
${ }^{33}$ Ahmad, Fuad Said, Sejarah Syaikh Abdul Wahab Tuan Guru Babussalam, 111.
}

diikuti oleh masyarakat di Desa Rantau Panjang Kiri

$\begin{array}{crr}\text { Adapun } & \text { strategi } & \text { dalam } \\ \text { mempertahankan } & \text { ajaran } & \text { tarekat }\end{array}$ naqsyabandiyah yang telah diikuti oleh masyarakat di Desa Rantau Panjang Kiri di dusun Tanjung Masjid I yaitu: 1) Mursyid tetap masuk walaupun jumlah jamaah sedikit, dengan waktu yang telah ditentukan 5x dalam setahun; 2) Menyampaikan antara Mursyid dengan murid dan murid yang satu dengan murid yang lainnya bahwa Tarekat ini tidak boleh dibiarkan begitu saja; 3) Berpindah-pindah dari satu daerah ke daerah lainnya; 4) Dikarenakan sistem yang digunakan oleh tarekat naqsyabandiyah ini adalah sistem turun-temurun, jadi, ketika Zuriat (keturunan) sudah tidak ada lagi maka jamaah bermusyawarah atau mufakat untuk mengangkat mursyid dari murid yang tertua dan memiliki ilmu yang lebih tentang ilmu tarekat naqsyabandiyah dari yang lainnya.

Begitu pula tarekat naqsyabandiyah yang ada di dusun Tanjung Masjid II desa Rantau Panjang Kiri juga memiliki strategi dalam mempertahankan ajaran-ajaran tarekatnya dengan cara: 1) Rutinitas masuk suluk yang telah terjadwal dan bertepatan pada bulan-bulan yang mulia, seperti: bulan Muharram, bulan Sya'ban, bulan Ramadhan dan bulan Dzulhijjah; 2) Menghidupkan Khatam Tawajuh pada malam Selasa dan malam Jum'at (diluar persulukan); 3) Melengkapi pembiayaan (fasilitas); 4) Berdakwah Secara terbuka.

Faktor pendukung dan penghambat dalam pengembangan dakwah Tarekat Naqsyabandiyah di Desa Rantau Panjang Kiri

Adapun faktor pendukung bagi mursyid persulukan di dusun Tanjung Masjid I desa Rantau Panjang Kiri yaitu: 1) Ilmu dalam bersuluk sangatlah bermanfaat untuk dunia-akhirat; 2) Mudah dalam semua urusan; 3) Ilmu tarekat naqsyabandiyah sudah menjadi darah daging, karena berasal dari nenek-moyang 
bagi yang telah mengikuti Taekat Naqsyabandiyah ini. Sedangkan faktor pendukung bagi seorang murid yaitu kemauan yang kuat untuk mendalami halhal keghaiban.

Adapun faktor penghambat bagi mursyid persulukan di dusun Tanjung Masjid I desa Rantau Panjang Kiri yaitu: 1) Dana (ekonomi); 2) Tempat persulukan yang kurang layak untuk ditempati; 3) Sakit atau badan kurang sehat; 4) Kesibukan dari jamaah itu sendiri. ${ }^{34}$ Sedangkan faktor penghambat bagi seorang murid adalah masalah dana, waktu dan fasilitas yang ada kurang memadai. ${ }^{35}$

Demikian pula persulukan di dusun Tanjung Masjid II juga memiliki faktor pendukung baik bagi mursyid maupun murid. Adapun faktor pendukung bagi mursyid yaitu: 1) Fasilitas mapan, dari beberapa segi, yaitu: pendanaan, pelayanan, bimbingan terhadap seluruh jamaah, ilmu dan adab Mursyid memadai (skill), perhatian masyarakat sangat antusias serta aparat Pemerintahan setempat (Kepala Desa); 2) Tempat yang strategis; 3) Dekat dari sumber air. Dan adapun faktor pendukung bagi murid yaitu fasilitasnya mapan (makan, minum, tempat dan kebutuhan lainnya) ditanggung oleh Mursyid dan masuknya pada bulan-bulan yang mulia.

Persulukan di dusun Tanjung Masjid II juga memiliki faktor penghambat yaitu: 1) Orang yang mau masuk ke dalam Tarkat Naqsyabandiyah (suluk) ini, sudah lanjut usia (uzur). Jadi, susah dalam mengajarkannya; 2) Jarak yang berjauhan sehingga komunikasi kurang efektif; 3)

\footnotetext{
${ }^{34}$ Wawancara dengan Kh. Dahnial, pada tanggal 28 Agustus 2015. Pada hari Jum'at pukul 10:00 s/d 11:25 WIB. Di rumah persulukan mursyid di Dusun Tanjung Masjid Rantau Panjang Kiri.

${ }^{35}$ Hasil wawancara dengan Khalijah (75) tahun,Hamidah (75 tahun), Shalbiyah (61 tahun), pada tanggal 15 Desember 2015, Hari Selasa, Pukul: 17:00-17:47 WIB. Dikediaman beliau di Dusun Tanjung Masjid II Kepenghuluan Rantau Panjang Kiri.
}

Kemauan dan waktu yang dimiliki oleh murid serta masyarakat tidak tepat.

\section{A. Kesimpulan}

Setelah dilakukan kajian yang mendalam tentang dapat disimpulkan bahwa strategi Tarekat Naqsyabandiyah dalam pengembangan dakwah di Desa Rantau Panjang Kiri Kecamatan Kubu Babussalam Kabupaten Rokan Hilir masih memerlukan pembenahan. Pembenahan yang paling utama untuk diperbaiki adalah komunikasi. Baik Mursyid, murid maupun masyarakat hendaknya saling mendukung dalam pembangunan fisik, mental dan spritual. Agar Tarekat Naqsyabandiyah tetap tumbuh dan berkembang adalah terletak kepada Mursyid. Seorang Mursyid tidak boleh cacat fisik maupun non-fisik dikalangan masyarakat. Untuk memudahkan dalam pengembangan dakwah tarekat Naqsyabandiyah ini, hendaknya menjalin hubungan baik dengan Pemerintah, sehingga dalam urusan fasilitas terpenuhui.

\section{Bibliografi}

Akdon, 2009. Strategic Management For Educational Management Bandung: Alfabeta.

Al-Qur'an Terjemahan, 2007. Departemen Agama RI, Jakarta: CV Penerbit J-ART.

Aziz, Moh. Ali. 2004. Ilmu Dakwah, Jakarta: Kencana.

Eldin, Achyar. 2003. Dakwah Stratejik, Jakarta: Pustaka Tarbiatuna.

Jumantoro, Totok dan Amin Samsul Munir. 2005. Kamus Ilmu Tasawuf, Wonosobo: Amzah

Kabbani, Syekh Muhammad Hisyam. 2007. Tasawuf dan Ihsan AntiVirus Kebatilan dan Kezaliman, Jakarta: Serambi

Mulyati, Sri. 2006. Tasawuf Nusantara (Rangkaian Mutiara Sufi Terkemuka), Jakarta: Kencana. 
Idarotuna, Vol. 1. No. 1. Oktober 2018

Mulyati, Sri. 2011. Tarekat-tarekat Muktabarah di Indonesia, Jakarta: Kencana.

Penyusun, Dewan Redaksi Ensiklopedi Islam. 2001. Enseklopedi Islam, Jakarta: PT Ichtiar Baru van Hoeve.

Perdamaian. 2010. Akhlak Tasauf, Pekanbaru: Unri Press.

Rusli, Ris'an. 2013. Tasawuf dan Tarekat, Jakarta: Rajawali Pers.

Said, Ahmad Fuad. 1976. Sejarah Syaikh Abdul Wahab Tuan Guru Babussalam, Medan: Pustaka Babussalam.

Syamsuddin, Din. 2002. Etika Agama dalam Membangun Masyarakat Madani, Jakarta: PT Logos Wacana Ilmu.

Zulkifli dan Santoso Sentot Budi. WUJUD (Menuju Jalan Kebenaran), Solo: CV. Mutiara kertas. 